\title{
Incidence of congenital syphilis in the State of Rio Grande do Norte and Brazil: a retrospective study
}

Gislanne S. E.Da Silva1, A. De A. Soares', Ana Beatriz D. Do Nascimento', Graciane P. De Souza', Franklin L. B. De Oliveira ${ }^{2}$ and Dany G. Kramer ${ }^{3^{*}}$

${ }^{1}$ Student. Federal University of Rio Grande do Norte / Faculty of Health Sciences of Traíri - Brazil.

${ }^{2}$ Prefeitura Municipal de Equador/ Rio Grande do Norte - Brazil.

${ }^{3}$ Prof. Dr. Federal University of Rio Grande do Norte / Faculty of Health Sciences of Traíri - Brazil.

\begin{abstract}
Introduction: Syphilis is an infection with increasing incidence in Brazilian regions, and the congenital form is liable to lead to cerebral palsy and musculoskeletal deformity. The objective of this study was to analyze the prevalence of congenital syphilis in the State of Rio Grande do Norte, Brazil.

Methods: An exploratory and retrospective study was performed from 2015 to 2017. Public domain data and unrestricted access were used in the DATASUS computer department through the TABNET application. The following variables were collected: age range, clinical evolution (congenital syphilis late, late congenital syphilis, stillbirth / syphilis abortion, ignored / blank, discarded; live birth), mother's schooling, performed prenatal and residence zone.

Results: In Brazil, there were 75,733 cases, whereas in the State of Rio Grande do Norte there were 1,436 cases of congenital syphilis, out of which a greater number of confirmed cases affected age group of 0-6 days (97.6\%). The highest number of cases was observed in the city of Natal (75.8\%), followed by Mossoró (7.8\%) and Parnamirim (5.7\%).

Conclusion: The study shows that the incidence of congenital syphilis occurs predominantly in incomplete elementary schooling and in the urban area. It was also verified that the diagnosis of most cases of congenital syphilis occurred in the age group up to 6 days of life, which contributes to the rates of evolution with the living child. In addition, a greater number of confirmed cases of congenital syphilis were observed, and prenatal care was performed, indicating a serious failure in care.
\end{abstract}

Key-words: Congenital syphilis, incidence, Brazil

\section{Introduction}

Syphilis is a sexually transmitted infectious disease which is a challenge for society and is considered a serious public health problem worldwide, despite the availability of low-cost diagnoses and effective treatment since the 1950s (Qin et al., 2014; Feitosa et al., 2016). The disease shows a worse scenario than the vertical transmission of human immunodeficiency virus (HIV) and is a determining factor in the rise of maternal mortality and indicators of perinatal morbidity and mortality (Carvalho \& Brito, 2014; Cavalcante \& Pereira, 2017; Whitham et al., 2018). Congenital syphilis (CS) is a traditional sentinel event in the monitoring of primary health care (PHC) (Feitosa et al., 2016; Woziank et al., 2017). As CS is easy to prevent, its occurrence suggests failures in the primary health care network or its integration with the general health system (Ministério da Saúde, 2011; Domingues et al., 2013). Its occurrence is associated with the inadequate management of cases with loss of opportunity both for diagnosis and treatment, absence of counseling, lack of partner treatment and inadequate treatment of diagnosed cases (Domingues et al., 2013; Quin et al., 2014; Feitosa et al., 2016; Torrone \& Miller, 2018).

One-third of pregnancies in women infected with Treponema pallidum who are treated improperly will result in fetal loss, and a third will lead to children with CS. Proper responses to this problem during the prenatal period may reduce the incidence of CS to less than $0.5 / 1,000$ live births (Ib) (Araujo et al., 2012; Domingues et al., 2013). In addition to its effects on mortality, preterm birth, low birth weight and acute complications, CS is also associated with deformities, neurological damage and other sequelae (Araujo et al., 2012; Domingues et al., 2013; Adeyinka et al., 2017).

*Corresponding E-mail: dgkcs@yahoo.com.br 
According to the World Health Organization (WHO), it is estimated that 5.6 million syphilis cases worldwide will occur by 2017, in which approximately 1 million pregnant women are affected by syphilis each year, causing more than 300 thousand fetal and neonatal deaths (Feitosa et al., 2016; Whitham et al., 2018; Torrone \& Miller, 2018). In Brazil, in 2016 a total of 87,593 cases of acquired syphilis were reported, 37,436 cases of syphilis in pregnant women and 20,474 cases of congenital syphilis, which totaled 185 deaths. Analyzing the rates by individualizing the States, congenital syphilis is evidenced in a greater number of cases in Espírito Santo, Rio de Janeiro, Rio Grande do Sul and Pernambuco (Cooper et al., 2016; Brazil, 2017).

Considering the occurrence of an increase in the number of cases of congenital syphilis due to easily modifiable factors, the present study aimed to determine the incidence of congenital syphilis by region of notification and in Rio Grande do Norte, aiming for the possibility of case reduction disseminating information about the disease.

\section{Materials and Methods}

\section{Study description}

A descriptive, retrospective and quantitative study using data from the computerized department of the single health system (DATASUS) through the TABNET application was done using public domain data and unrestricted access.

\section{Study area}

The data collected refer to all confirmed cases of congenital syphilis in women living in the state of Rio Grande do Norte, Northeast Brazil, , recorded in the years 2015 to 2017, a period that refers to the last two years with data available in the system. This state presents as main cities: Natal (capital), Mossoró, Paramirim and Caíco (Instituto Brasileiro de Geografia e Estatística, 2010).

\section{Data collection}

The following variables were selected and arranged in the form of tables: age range (up to 6 days, 7 to 27 days, 28 days at <1 year, 1 year, 2 to 4 years, 5 to 12 years), evolution (congenital syphilis late, late congenital syphilis, stillbirth / syphilis abortion, ignored / blank, discarded; live birth), mother's schooling (illiterate, fundamental incomplete, complete fundamental, incomplete middle, complete middle, incomplete superior, complete superior, ignored / blank), performed prenatal and residence zone (urban, rural and peri-urban). The data were tabulated and analyzed in the Tabwin program, in which it was possible to generate graphs and tables used in the text illustration.

\section{Results}

Data on the numbers of congenital syphilis cases at the national level and specifically in Rio Grande do Norte were analyzed, and 1,436 cases were reported in the years 2015 to 2017. This analysis was performed based on data from DATASUS. Cases confirmed second diagnosis year in the period: 2015-2017. At national level, 75,733 cases of congenital syphilis were observed in the Southeast region (42.4\%) followed by the Northeast region (28.3\%), the South region (14.5\%), North region (8.6\%) and Central-West region (5.9\%) - Figure 01. 


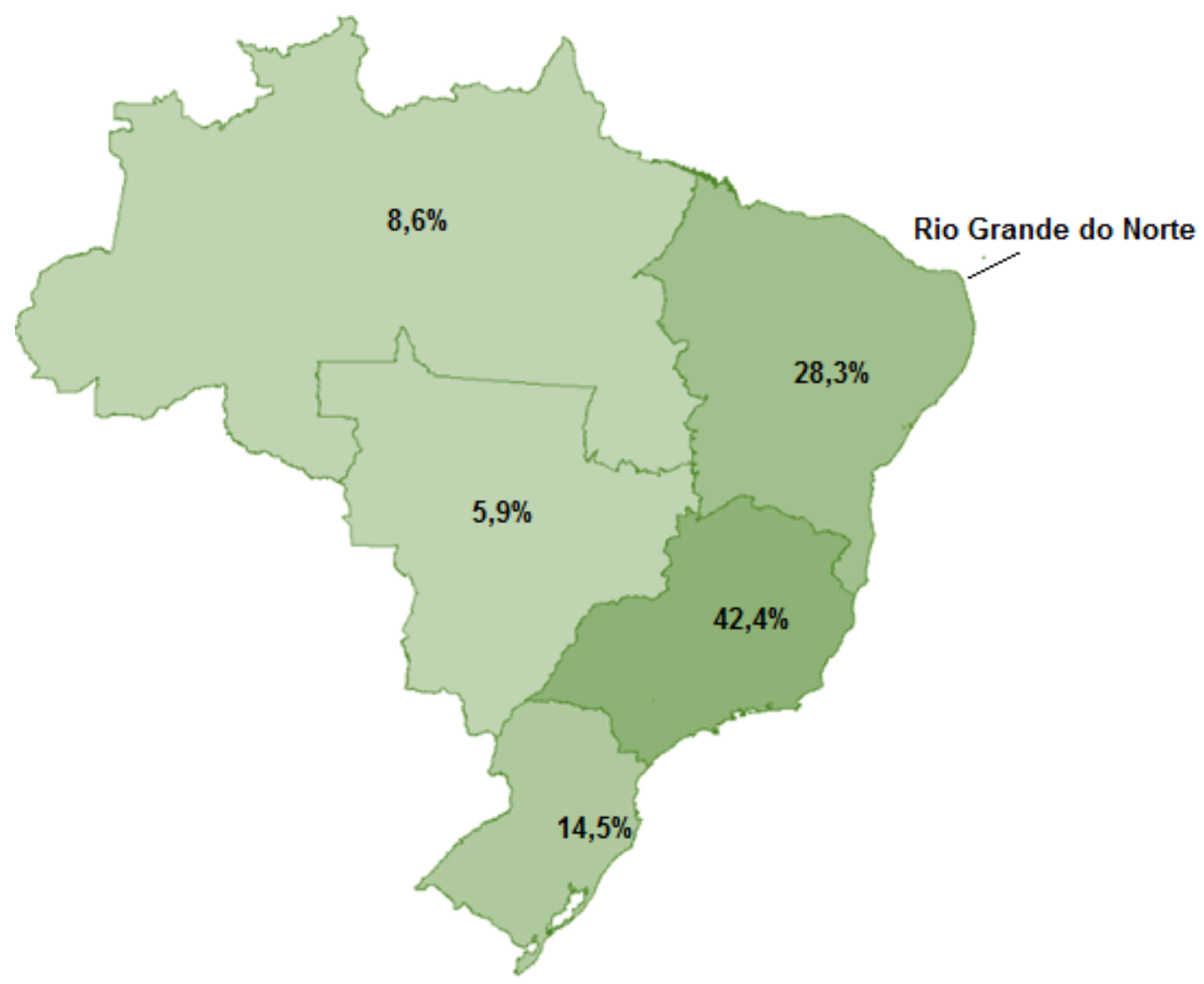

Figure 1. Confirmed cases of congenital syphilis in the national territory

According to DATASUS, in Rio Grande do Norte, between 2014 and 2016, there were 142,576 live births, of which 1,274 were reported with congenital syphilis and in the period from 2015 to 2017, 1,436 cases were confirmed. Figure 2 shows the spatial distribution of the reported confirmed cases of congenital syphilis according to the municipality of residence. There were a greater number of cases of congenital syphilis in the state capital, Natal (75.8\%) followed by Mossoró (7.8\%), Parnamirim (5.7\%) and Santa Cruz (3.4\%).

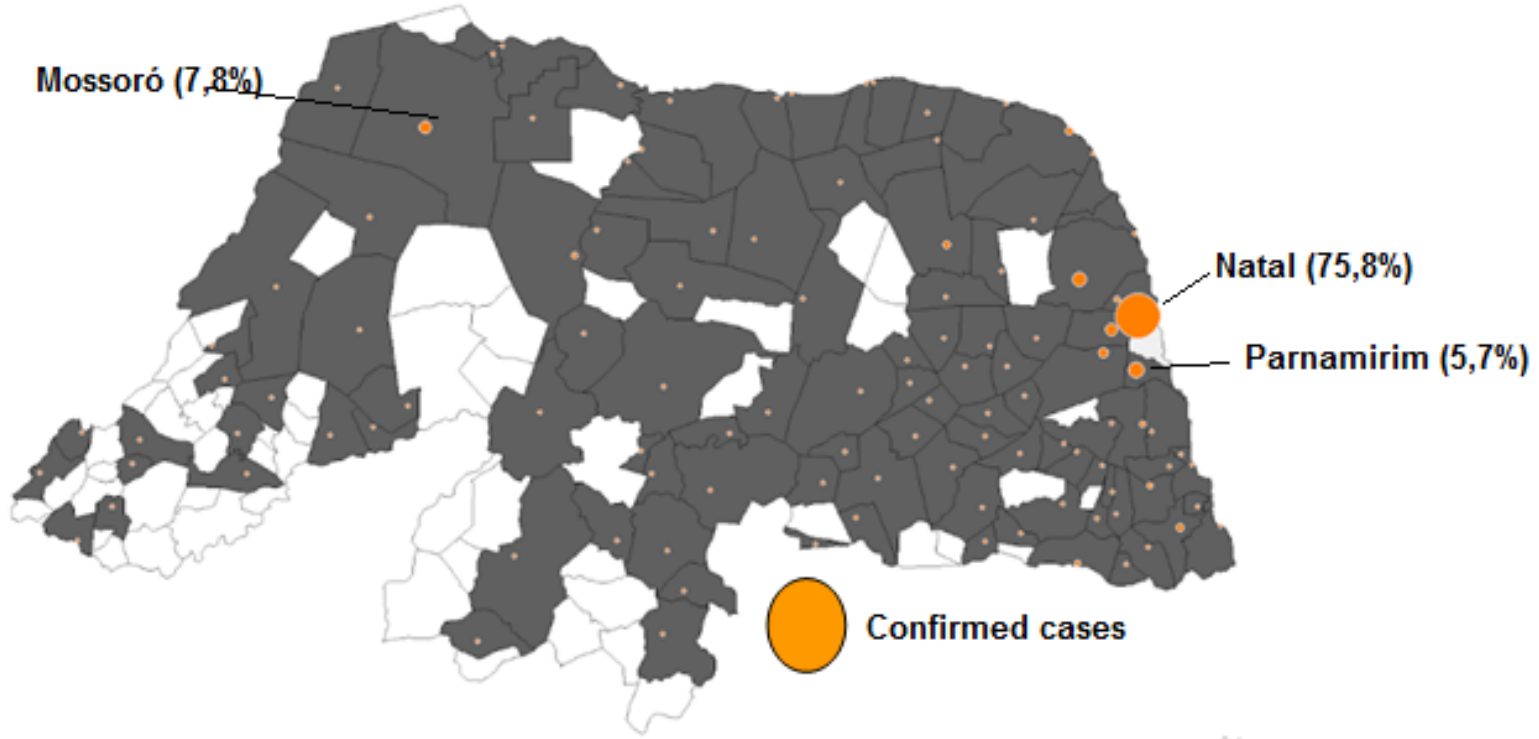

Figure 2. Spatial distribution of confirmed cases of congenital syphilis according to the municipality of residence, Rio Grande do Norte, Brazil, 2015-2017 
Of the 1,436 cases of congenital syphilis, a higher number of confirmed cases in the age group to 6 days (97.6\%) was identified, evolving with a live child (95\%) (Table 1), where most were classified as recent congenital syphilis ( $91 \%$ ) (Table 2 ), in which mothers had incomplete primary education (47.1\%) (Table 3). The diagnosis of $85.3 \%$ was from prenatal follow-up (Table 4 ).

Table1. Confirmed cases of congenital syphilis according to the age range and evolution of the child, Rio Grande do Norte, Brazil, 2015-2017.

\begin{tabular}{|c|c|c|c|c|c|}
\hline & & \multicolumn{4}{|c|}{ Year } \\
\hline & & 2015 & 2016 & 2017 & Total \\
\hline \multirow{7}{*}{ Age group } & Up to 6 days & 501 & 429 & 429 & 1,402 \\
\hline & 7-27 days & 4 & 7 & 7 & 16 \\
\hline & 28 days to $<1$ year & 8 & 10 & 10 & 26 \\
\hline & 1 year (12 to 23 months) & 0 & 1 & 1 & 2 \\
\hline & 2 a 4 years & 1 & 1 & 1 & 2 \\
\hline & 5 a 12 years & 0 & 0 & 0 & 2 \\
\hline & Total & 514 & 448 & 474 & 1,436 \\
\hline \multirow{6}{*}{ Evolution } & & 2015 & 2016 & 2017 & Total \\
\hline & Ignored / white & 18 & 15 & 12 & 45 \\
\hline & Live & 481 & 425 & 458 & 1,364 \\
\hline & Death by notified act & 7 & 5 & 2 & 14 \\
\hline & Death by another cause & 1 & 1 & 1 & 3 \\
\hline & Total & 507 & 446 & 473 & 1,436 \\
\hline
\end{tabular}

Table 2. Cases confirmed by Diagnostic Year according to Final Classification

\begin{tabular}{lrrrr}
\hline Final Classification & $\mathbf{2 0 1 5}$ & $\mathbf{2 0 1 6}$ & $\mathbf{2 0 1 7}$ & Total \\
\hline Ignored / white & 26 & 51 & 38 & 115 \\
Recent Congenital Syphilis & 481 & 394 & 433 & 1,308 \\
Late Congenital Syphilis & 1 & 1 & 2 & 4 \\
Stillbirth / Abortion for Syphilis & 1 & - & - & 1 \\
Discarded & 5 & 2 & 1 & 8 \\
\hline Total & 514 & 448 & 474 & $\mathbf{1 , 4 3 6}$ \\
\hline
\end{tabular}


Table 3. Cases confirmed by schooling according to diagnosis year.

\begin{tabular}{lrrrr}
\hline Mother's Educational level & $\mathbf{2 0 1 5}$ & $\mathbf{2 0 1 6}$ & $\mathbf{2 0 1 7}$ & Total \\
\hline Ignored / white & 129 & 102 & 67 & 298 \\
Illiterate & 5 & 5 & 4 & 14 \\
Incomplete elementary school & 220 & 198 & 259 & 677 \\
Complete primary education & 46 & 25 & 23 & 94 \\
Incomplete high school & 50 & 56 & 65 & 171 \\
Complete high school & 54 & 54 & 52 & 160 \\
Incomplete higher education & 5 & 4 & 3 & 12 \\
Complete higher education & 2 & 2 & & 4 \\
Not applicable & 3 & 2 & 1 & 6 \\
\hline Total & $\mathbf{5 1 4}$ & $\mathbf{4 4 8}$ & $\mathbf{4 7 4}$ & $\mathbf{1 , 4 3 6}$ \\
\hline
\end{tabular}

Table 4. Cases confirmed by performed Pre-natal according to year Diagnosis

\begin{tabular}{lrrrr}
\hline Carried prenatal?? & $\mathbf{2 0 1 5}$ & $\mathbf{2 0 1 6}$ & $\mathbf{2 0 1 7}$ & Total \\
\hline lgnored/white & 27 & 11 & 15 & 55 \\
Yes & 419 & 388 & 418 & 1,225 \\
No & 68 & 49 & 41 & 158 \\
\hline Total & 514 & 448 & 474 & $\mathbf{1 , 4 3 6}$ \\
\hline
\end{tabular}

Table 5. Confirmed cases by Residence Zone according to Year Diagnosed

\begin{tabular}{lrrrr}
\hline Home area & $\mathbf{2 0 1 5}$ & $\mathbf{2 0 1 6}$ & $\mathbf{2 0 1 7}$ & Total \\
\hline Ignored/ white & 11 & 13 & 474 & $\mathbf{3 9}$ \\
Urban & 434 & 361 & 389 & $\mathbf{1 , 1 8 4}$ \\
Rural & 66 & 74 & 70 & $\mathbf{2 1 0}$ \\
Peri-urban & 3 & 0 & 0 & $\mathbf{3}$ \\
\hline Total & 514 & 448 & 474 & 1,436 \\
\hline
\end{tabular}

\section{Discussion}

In the studied period, Rio Grande do Norte presented a congenital syphilis rate of $1.9 \%$ of registered cases in Brazil. Despite being a relatively small number of cases in the state, considering the size of the national territory, syphilis is still a problem that nedds attention at the state level for actions to prevent and eradicate the disease. The year 2015 had the highest number $(35.7 \% ; n=513)$ of such occurrences in the state. Among the municipalities with the highest number of notifications, between 2015 and 2017 is the state capital, Natal, with 1,089 confirmed cases (75.8\%), in which the reason for this high index can be justified because it is the city with the greatest population density. The data available on DATASUS are subject to revision and updates.

The rate of congenital syphilis had a reduction in 2016, with an increase in the following year, 2017. This inconstancy can be due to lack of follow-up during prenatal care or failure to perform treatment according to the therapeutic regimen (Feitosa et al., 2016). In this way, the 
strategies for conducting preventive campaigns are an important factor for the reduction of syphilis cases, as well as the rapid test favors the diagnosis and treatment in an early manner reducing the cases of congenital syphilis.

Carvalho and Brito (2014) report that the Health Ministry of Brazil, as signatory of an international agreement to eliminate congenital syphilis, has carried out actions to achieve this objective, focusing on the appropriate treatment, integration with other health programs, systems active local monitoring and consequent interruption of the transmission chain. However, many of these procedures have not been performed.Therefore, the results obtained are not in accordance with the goal of the Pan American Health Organization (PAHO) (CARVALHO and Brito; 2014; Feitosa et al., 2016) for the elimination of the disease, as, according to Ordinance No. 3,242, DECEMBER 30, 2011, by 2015, incidence of congenital syphilis should be less than $0.5 / 1000$ live births.

According to Rocha et al. (2015), there is a tendency for infectious diseases to have a high incidence in larger municipalities, possibly due to a higher rate of dissemination in environments with a high population density. In the present study, the municipality with the highest number of reported cases was capital city Natal, followed by Mossoró, in which, according to IGBE demographic census (2010), they are both municipalities with the highest demographic density in the state, which may justify the highest occurrence of cases. Thus, these municipalities require greater attention and adherence to preventive measures, with the participation of managers and health professionals able to carry out health education about the disease with the purpose of providing means of prevention in these places. The results showed that in most cases syphilis occurred in women with low schooling residing in urban areas. Similar to the one observed by Dantas et al., (2017), in which, 67\% of mothers reported they had only attended elementary school. In this way, this fact proposes that those are groups more susceptible to infection, indicating the instance of greater attention of the control programs.

In this study it was observed that most of the cases obtained as final congenital syphilis final classification. Wijesooriya et al (2016) reports that congenital syphilis can be classified as recent or late, where signs and symptoms are observed up to the second year of life or after the second year of life.

Natal, the capital city of Rio Grande do Norte, was the municipality that presented the highest number of cases of congenital syphilis. The study shows that the incidence of congenital syphilis occurs predominantly in incomplete elementary schooling and in the urban area. It was also verified that the diagnosis of most cases of congenital syphilis occurred in the age group up to 6 days of life, which contributes to the rates of evolution with the living child. In addition, a greater number of confirmed cases of congenital syphilis were observed, and prenatal care was performed, indicating a serious failure in care. Therefore, the need for greater attention of the Family Health Strategy in the identification, follow-up and treatment of confirmed cases, with syphilis testing of all pregnant women, diagnosis and timely treatment is reinforced, leading to a greater probability of reducing the rate of syphilis congenital and the evolution to death by notified. It is also necessary the continuous accomplishment of actions of health promotion, stimulating the accomplishment of prenatal, being this a factor of fundamental importance for the prevention of maternal and child health, making possible the diagnosis of numerous diseases.

\section{Ethical considerations}

The collected data do not provide identification of the patient in the system, which guarantees the non-identification of the cases, granted by the resolution of the National Health Council CNS n. $466 / 2012$.

Competing interests: We declare no conflicts of interest with the authors involved in the study.

Acknowledgement: We thank Propesq / UFRN for the technical support for the research. 


\section{References}

ADEYINKA, D. A., OLAKUNDE, B. O., OZIBUE, Z. O. (2017) Elimination of mother-to-child transmission of syphilis: Is it a reality in Nigeria by 2020? Scandinavian Journal of Public Health, 1-4.

ARAÚJO, C.L., SHIMIZU, H.E., ALVES DE SOUSA, A.I. \&HAMANN E.M. (2012). Incidence of congenital syphilis in Brazil and its relationship with the Family Health Strategy. Revista de SaúdePública, [s.I.], v. 46, n. 3, p.479-486.

DANTAS, L.A., JERÕNIMO, S.H.N.; TEIXEIRA, G. A. (2017) Epidemiologic profile of acquired syphilis diagnosed and notified at a maternal-child university hospital. Enfermeria Global, n. 46,

DATASUS/TABNET - DEPARTAMENTO DE INFORMÁTICA DO SUS. Disponívelem: <http://tabnet.datasus.gov.br/cgi/tabcgi.exe?sinannet/cnv/sifilisrn.def>. Acessoem: 22 out. 2018.

DOMINGUES, R.M.S.M., SARACEN, V.,HARTZ, Z.M.A.\& LEAL, M.C. (2013).Sífiliscongênita: eventosentinela da qualidade da assistênciapré-natal. Revista de SaúdePública, vol.47, no.1.

CARVALHO, I, \& BRITO, R. (2014). Congenital syphilis in the state of Rio Grande do Norte: a descriptive study in the period 2007-2010. Epidemiol. Serv. Saúde, Brasília, v. 2, n. 23, p.287-294.

CAVALCANTE, P. \& PEREIRA, R. B. (2017). Syphilis in pregnancy and congenital syphilis in Palmas, Tocantins State, Brazil, 2007-2014. Epidemiol. Serv. Saude, Brasília, 26(2).

COOPER, J. M \& SÁNCHEZ, P.J. (2018). Congenital syphilis. Seminars In Perinatology, [s.l.], v. 42, n. 3, p.176184.

COOPER, J. M., MICHEL, I. C. \& WOZNIA, I. C.In time: the persistence of congenital syphilis in Brazil - More progress needed!.Rev. paul. pediatr. vol.34 no.3 São Paulo July/Sept. 2016

FEITOSA, J.A.S., ROCHA, C.H.R. \& COSTA., F.S (2016). Artigo de Revisão: Sífilis congênita. Revista de Medicina e Saúde de Brasília, 5(2): 286-97.

HAYES, J. \& WHIPKEY, K. (2016).Congenital syphilis in Nigeria, Zambia, and India: identifying policy pathways to eliminate mother-to-child transmission of syphilis. PATH.

Instituto Brasileiro de Geografia e Estatística - IBGE [homepage na Internet]. [acessoem 2018 Out 10]. CensoDemográfico 2010; [aproximadamente 2 telas]. Disponívelem: https://cidades.ibge.gov.br/brasil/rn/panorama.

Ministério da Saúde (BR). Portaria $n^{\circ}$ 3242, de 30 de Dezembro de 2011. Dispõesobre o fluxograma laboratorial da sífilis e autilização de testes rápidos para triagem da sífilis em situações especiais e apresenta outras recomendações. DiárioOficial da União, Brasília, p. 50, 2 jan. 2012. Seção 1.

BRAZIL. MINISTÉRIO DA SAÚDE (2017). Boletim epidemiológico. Brasília.

ROCHA, L. E. C., THORSON, A. E.\& LAMBIOTTE, R (2015). The non-linear health consequences of living in larger cities. Journal of Urban Health92(5):785-99.

QIN, J., TIE-JIAN, F. \&TU-BAO, Y. (2014). Factors for Congenital Syphilis and Adverse Pregnancy Outcomes in Offspring of Women With Syphilis in Shenzhen, China: A Prospective Nested Case-Control Study. Sexually Transmitted Diseases, Volume 41 - Issue 1 - $p$ 13-23.

TORRONE, E. A. \& MILLER, W. (2018).Congenital and Heterosexual Syphilis: Still Part of the Problem. Sexually Transmitted Diseases: Volume 45 - Issue - p S20-S22

WHITHAM, M., BANDY, S. \& EPPES, C. (2018).Maternal Characteristics of Congenital Syphilis. Obstetrics \& Gynecology. 131:101S.

WIJESOORIYA, N,S., ROCHAT, R.W., KAMB, M.L., TURLAPATI, P., TEMMERMAN, M., BROUTET, N. \& NEWMAN, L.M. (2016). Global burden of maternal and congenital syphilis in 2008 and 2012: a health systems modelling study. The Lancet Global Health, [s.l.], v. 4, n. 8, p.525-533, ago. 2016.

WOZNIAK, P. S., CANTEY, J. B. \& ZERAY, F. (2017). Congenital syphilis in neonates with nonreactive nontreponemal test results. Journal of Perinatology volume 37:1112-1116. 